PONTIFÍCIA UNIVERSIDADE CATÓLICA DO RIO DE JANEIRO

\title{
A experiência do teletrabalho para estagiários durante a pandemia do coronavírus
}

Beny Gorin Vaisman

Trabalho de Conclusão de Curso

Centro de CIÊNCIAS SOCIAIS - CCS

DEPARTAMENTO dE AdMINISTRAÇÃO

Graduação em Administração de Empresas 
Beny Gorin Vaisman

\section{A experiência do teletrabalho para estagiários durante a pandemia do coronavírus}

Trabalho de Conclusão de Curso

Trabalho de Conclusão de Curso, apresentado ao programa de graduação em Administração da PUC-Rio como requisito parcial para a obtenção do título de graduação em Administração.

Orientador(a) : Ana Heloisa da Costa Lemos

Rio de Janeiro, novembro de 2021 


\section{Agradecimentos}

A partir do quinto período da faculdade comecei a pensar em qual tema iria trabalhar na monografia. Dentro da área de organizações quase tudo me interessava, porém foi apenas com o início do estágio e consequente trabalho no modelo híbrido que descobri o que realmente queria estudar: a experiência do estágio dentro do modelo remoto de trabalho.

O trabalho foi bastante intenso e desafiador, sobretudo para realizar as entrevistas e gerar uma análise relevante. Isso não seria possível sem o apoio de muitas pessoas que de formas diferentes puderam contribuir para mais essa etapa concluída.

Em primeiro lugar, agradeço aos meus pais, Marcelo e Tania, e meu irmão, Flavio que me incentivaram e acreditaram sempre no meu potencial, mesmo nas horas mais difíceis. Tenho certeza de que os investimentos material e imaterial que contribuíram para minha formação terão um grande retorno no futuro.

Agradeço muito à minha orientadora Ana Heloísa da Costa Lemos pelo apoio em todo o trabalho, desde a disciplina de projeto de monografia até todo o desenvolvimento do tema, sempre com observações e questionamentos muito relevantes. Agradeço imensamente também ao Christian Kazuo, doutorando na PUC, que tanto me ajudou com as principais referências sobre o tema, observações e correções valiosas.

Por último, agradeço a todos aqueles que contribuíram e participaram da minha vida nesse período como amigos, familiares e colegas de trabalho.

Obrigado! 


\section{Resumo}

Vaisman, Beny Gorin. A experiência do teletrabalho para estagiários durante a pandemia do coronavírus. Rio de Janeiro, 2021. Número de páginas 32. Trabalho de Conclusão de Curso - Departamento de Administração. Pontifícia Universidade Católica do Rio de Janeiro.

A pandemia da COVID-19, iniciada em março de 2020, teve consequências enormes no mundo do trabalho. Muitos trabalhadores, de forma inesperada e emergencial, foram obrigados a trabalhar de forma remota, transferindo o escritório para as próprias casas. Os estagiários, iniciantes no mercado e buscando ainda sua inserção profissional, tiveram desafios ainda maiores decorrentes do isolamento social, como o distanciamento dos gestores, a dificuldade de aprendizado e os ruídos de comunicação. Nesse sentido, o presente estudo tem como objetivo entender como foram as experiências de estágio, iniciadas durante a pandemia, no modelo de teletrabalho, para estudantes universitários dos cursos de Administração, Economia e Comunicação. Para isso, foi realizada uma pesquisa qualitativa com 9 estagiários dentro desses requisitos. Os resultados sugerem que a experiência remota tem como benefícios a ausência de deslocamento e a maior capacidade conciliar a vida pessoal e profissional. Por outro lado, como aspectos críticos, observou-se o distanciamento do gestor e colegas e a falta do "sentir" empreserial, com base no ambiente físico.

\section{Palavras-chaves}

Estágio. Teletrabalho. Home-office. Covid-19.

\section{Abstract}

Vaisman, Beny Gorin. A experiência do teletrabalho para estagiários durante a pandemia do coronavírus. Rio de Janeiro, 2021. Número de páginas 32. Trabalho de Conclusão de Curso - Departamento de Administração. Pontifícia Universidade Católica do Rio de Janeiro

The COVID-19 pandemic, which began in March 2020, had enormous consequences in the job market. Many workers, unexpectedly and urgently, were forced to work remotely, transferring the office to their own homes. The interns, new to the market and still seeking for professional insertion, had even greater challenges arising from social isolation, such as distance from managers, learning difficulties and communication failure. In this regard, the present study aims 
to understand how the internship experiences, initiated during the pandemic, in the teleworking model, are being for university students from Administration, Economics and Communication courses. For that purpose, a qualitative research was carried out with 9 interns within these requirements. The results suggest that the remote experience has the benefits of the absence of displacement and greater ability to reconcile personal and professional life. On the other hand, as critical aspects, there was the distance of the manager and colleagues and the lack of business "feeling", based on the physical environment.

Key-words:

Internship. Remotework. Telework. Home-office. Covid-19. 


\section{Sumário}

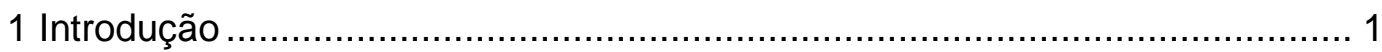

2 Referencial Teórico ........................................................................ 3

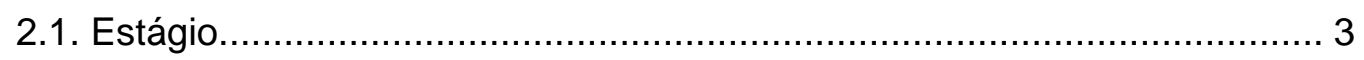

2.2. Teletrabalho nas organizações ........................................................ 5

2.2.1. Surgimento e desdobramentos históricos do teletrabalho ................. 5

2.2.2. Multiplicidade do termo........................................................ 6

2.2.3 Contextualização nacional...................................................... 7

2.2.4. Benefícios e aspectos questionáveis do teletrabalho....................... 8

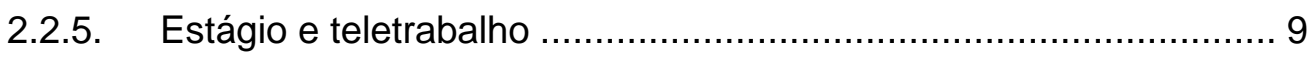

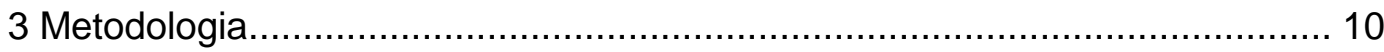

3.1. Tipo de pesquisa ................................................................ 10

3.2. O perfil do sujeito de pesquisa .................................................. 10

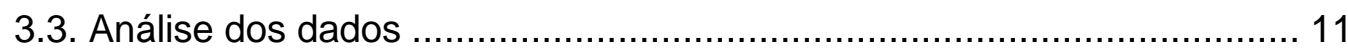

4 Apresentação e análise dos resultados ................................................. 12

4.1. Processo de ingresso e início do trabalho na empresa ......................... 12

4.2. Experiência de trabalho ........................................................... 17

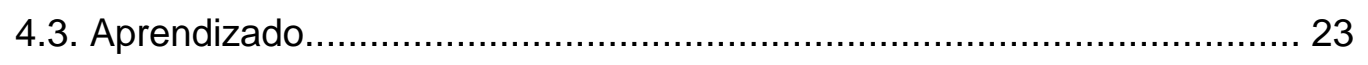

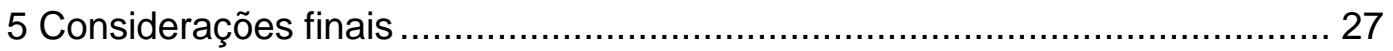

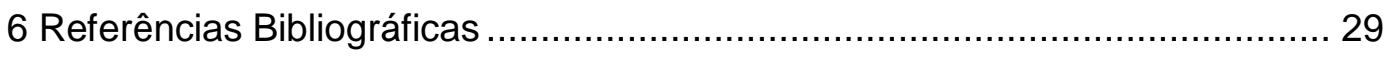

Anexo 1: Roteiro de Entrevista .......................................................... 33

\section{Lista de Tabelas}

Tabela 1: Perfil das entrevistadas Erro! Indicador não definido.1

Tabela 2: Categorias de análise Erro! Indicador não definido.2 


\section{Introdução}

Muitos estudantes universitários, especialmente dos cursos de Administração, Economia e Comunicação, desde o início da pandemia da Covid-19, se viram obrigados a estagiar em empresas e instituições de maneira parcial ou totalmente remota (VALOR, 2020). As pesquisas recentes sobre teletrabalho e estágio destacam que existem barreiras e dificuldades enfrentadas para o bom exercício de tal função no contexto descrito, além de benefícios e vantagens (FOLHA DIRIGIDA, 2021).

O estágio curricular obrigatório é uma oportunidade de exercício da atividade profissional para jovens estudantes, visando vivenciar práticas que complementam a formação teórica. Tal atividade deve promover um espaço de troca entre a experiência externa e interna de estudo (ANDRADE e RESENDE, 2015). Os pontos positivos do estágio são a conciliação entre teoria e prática, aprofundamento em uma área de maior interesse, entendimento da realidade de mercado, aumento do senso crítico. Já os negativos são o pouco tempo para realização do estágio; dificuldades no acesso a informação; aprofundamento de apenas um assunto; problemas na orientação e falta de encontros periódicos (BECKHAUSER, 2017).

Com a pandemia do Coronavírus, em março de 2020, outras barreiras começaram a ser enfrentadas pelos estagiários, e também pelos empregados, decorrentes do trabalho remoto total ou parcial implantado na maioria das organizações. Dentre elas, destacam-se: a distância dos supervisores; o pouco contato com as pessoas da empresa; a ausência de encontros e trocas não planejadas; o prejuízo nas relações pessoais; e o ambiente de trabalho em casa não adequado (FOLHA DIRIGIDA, 2021). Por outro lado, houve benefícios, destacados pela literatura, tais como: aumento da produtividade e motivação, economia de recursos financeiros e tempo de deslocamento, flexibilidade na jornada de trabaIho, autonomia (ADERALDO e LIMA, 2017).

Nesse contexto, o objetivo da presente pesquisa é entender como estão sendo as experiências estágio, iniciadas durante a pandemia, no modelo de tele- 
trabalho, para estudantes universitários dos cursos de Administração, Economia e Comunicação. Assim, as principais questões da pesquisa se referem à busca do entendimento acerca das expectativas dos jovens sobre seus estágios e qual foi a realidade encontrada, na modalidade do estágio remoto; como o teletrabaIho pode ter favorecido ou prejudicado essa experiência; quais os principais anseios e angústias dos jovens ao exercer o trabalho de forma remota.

As modalidades de cursos escolhidas visam contemplar grupos com ampla oferta de estágio, bem como incluir aquelas em que o mesmo é obrigatório na grade curricular. Além disso, em geral, as atividades exercidas pelos estagiários desses cursos são mais criativas ou estratégicas do que operacionais, como são em outros cursos, como engenharia. O curso de Administração, especificamente, já foi representado exclusivamente por classes mais favorecidas, porém hoje já pode se considerar um perfil socioeconômico mais diverso entre os estudantes (ROCHA DE OLVEIRA e PICCININI, 2012).

Esse estudo se torna relevante no contexto atual visto que a pandemia da Covid-19 mudou significativamente a forma como as empresas se estruturam e se organizam, afetando diretamente os estagiários com pouca ou nenhuma experiência no mercado de trabalho e permeados de expectativas sobre essa vivência. Por se tratar de um fenômeno ainda recente e em curso, o estudo é importante para entender os próximos passos de líderes, gestores e empresas na condução e orientação de seus estagiários que atuam na modalidade de teletrabalho e também para guiar esses estudantes para uma melhor experiência remota. Esse estudo pode agregar, portanto, com informações para as áreas de atuação profissional que tem visto uma transição parcial ou completa de seu trabalho

do presencial

para

0 remoto 


\section{Referencial Teórico}

\subsection{Estágio}

O estágio pode ser caracterizado como uma experiência complementar na formação do aluno,onde prioriza-se a possibilidade de integração entre teoria e prática, gerando reflexões, com respaldo dos referenciais teóricos proporcionados pelas instituições de ensino. É a articulação entre o saber, ensinado nas instituições, e o fazer, que se dá através da experiência prática do trabalho (ANDRADE, RESENDE, 2015). Dessa forma, a atividade do estágio busca consolidar o entendimento de conceitos a partir da vivência no dia a dia das organizações (BECKHAUSER, 2017).

Para Rocha-de-Oliveira e Piccinini (2012, p. 46), os estágios podem ser observados como uma forma de "inserção profissional organizada", na integração entre os sistemas educativo e produtivo, de forma que a própria universidade já ensina aspectos mais prático, preparando os jovens para o início de suas carreiras no mercado de trabalho. Essa visão é mais ampla se comparada à proposta inicial do estágio, em décadas anteriores, definida como uma forma de complementar a formação e acesso ao me

Essa prática se desenvolve em parte na esfera do trabalho, com o relacionamento de diferentes atores (estudantes, instituições de ensino, agentes de intermediação, organizações e o Estado) que buscam estabelecer normas e regras que as orientam e a partir dessas experiências, os estagiários constroem suas crenças e percepções sobre esse período (OLIVEIRA, PICCININI, 2012).

A Lei no 11.788 , de 25 de setembro de 2008, que regulariza a atividade do estágio hoje:

\footnotetext{
Art. 1ำ Estágio é ato educativo escolar supervisionado, desenvolvido no ambiente de trabalho, que visa à preparação para o trabalho produtivo de educandos que estejam frequentando o ensino regular em instituições de educação superior, de educação profissional, de ensino médio, da educação especial e dos anos finais do ensino fundamental, na modalidade profissional da educação de jovens e adultos. (BRASIL, 2008)
} 
Oliveira e Piccinini (2012) também destacam a necessidade de supervisão para essa atividade, priorizando sempre o desenvolvimento do aluno. Como ato educativo, requer que escola e empresa trabalhem de forma conjunta e didática com os estagiários, com relação às suas tarefas, avaliações e resultados (ANDRADE, RESENDE, 2015). Outro aspecto da nova lei é o entendimento do estágio como uma via de preparação para o mercado de trabalho, como responsável pela inserção profissional dos jovens (OLIVEIRA, PICCININI, 2012).

O estágio pode funcionar como forma de complementar a experiência acadêmica, trazendo uma vivência e uma interação com uma organização que pode ser construtiva para ele. Além disso, gera motivação ao estudo, facilita a assimilação de conteúdo e estimula a criatividade e senso crítico do estudante (BIANCHI, OLIVEIRA, 2011).

Estudos mostraram também que na visão dos estagiários, os fatores de maior importância da atividade são o processo de aprendizagem, a facilitação para inserção profissional e também um período de experimentação (BIANCHI, OLIVEIRA, 2011). Rocha de Oliveira e Piccinini (2012) destacam a importância desse período para a vida profissional dosestudantes, que contribui para o início de suas carreiras e suas escolhas futuras no mercado de trabalho. De acordo com Beckhauser (2017), o estágio tem como pontos positivos para o estudante, além dos já citados: direcionar o aluno a um aprofundamento na área de maior interesse; possibilitar a entrada no mercado de trabalho; aumentar o senso crítico.

Um aspecto relevante dentro da prática do estágio é a inserção do estudante em um novo ambiente e cultura ainda não vividos anteriormente, de forma que entrem em contato com valores, crenças e pressupostos básicos que são compartilhados pelos membros daquela organização (SCHEIN, 1988). Esse fato é extremamente relevante principalmente nos primeiros meses dos estagiários, durante o período de adaptação.

Por outro lado, algumas pesquisas retratam que os estágios estão muito distantes do seu objetivo pedagógico original, servindo como fonte de renda alternativa para os estudantes e como mão de obra de baixo custo para para as empresas, desempenhando atividades com baixo nível de exigência, pouco relacionadas com os aprendizados, além de fortalecer a concorrência entre eles (ROCHA DE OLVEIRA e PICCININI (2012). Valoria, Czarneski e Machado (2018) afirmam que durante muito tempo o estágio era visto como uma forma de 
contratação barata para as empresas, devido à baixa remuneração e alta motivação dos jovens em aprenderem e crescerem.

Callefi e Mello Neto (2019), a partir de uma pesquisa acerca das expectativas dos estagiários sobre o trabalho e o sofrimento gerado pelo mesmo, observaram que alguns fatores são recorrentes como: insatisfação, percepção de inutilidade do trabalho, trabalho sem sentido e desmerecimento da função. Os autores afirmam que, se em um primeiro momento há euforia e animação com o trabalho, com o passar do tempo, se torna monótono, sem objetivo de aprendizagem e desgastante.

Roesch (1996) reforça a utilização dessa modalidade de trabalho para tarefas repetitivas, específicas e que não dão a oportunidade de aprender e conhecer outras atividades, apesar de afirmar que a experiência de trabalho é sempre válida levando-se em conta os relacionamentos. Os dois estudos destacam que é preciso dar funções aos estagiários que realmente os dêem perspectivas profissionais e um plano de desenvolvimento claro.

\subsection{Teletrabalho nas organizações}

\subsubsection{Surgimento e desdobramentos históricos do teletrabalho}

O termo Telework foi cunhado por Niles em 1973, no contexto do desenvolvimento e mudanças nas telecomunicações e nas tecnologias da informação da época. Fazia referência à substituição parcial ou total do trajeto duas vezes ao dia para o trabalho pelo uso de telecomunicações e computadores (Niles, 1988). Posteriormente, Van Sell e Jacobs (1994) o caracterizaram pela utilização de computadores e equipamentos de telecomunicações para trabalhar em casa ou em um local remoto, um ou mais dias por semana.

A Organização Internacional do Trabalho (OIT, 2017) define teletrabalho como aquele exercido "distante dos escritórios ou da oficinal central" no qual os trabalhadores "mantém-se conectados por meio de novas tecnologias". (HAUBRICH, FROEHLICH, 2020). Em contrapartida, Costa (2007) aponta que a modalidade pode ser compreendida como resultado da reestruturação de capital, daatividade do trabalho e dos mercados.

Segundo Tremblay (2002), a maior parte das pesquisas sobre teletrabalho referem-se ao trabalho em domícilio, porém existem diversas outras formas: (a) 
o trabalho móvel executado em vários lugares fora do escritório central (pelos representantes de vendas, técnicos, etc.); (b) o trabalho executado por uma série de firmas com telecentros; e (c) o trabalho executado pelos trabalhadores de uma mesma empresa em escritórios-satélites.

O teletrabalho teve como principal motivação inicial o desejo das organizações de empregar trabalhadores distantes dos escritórios ou fábricas, passando a considerar áreas geográficas antes inviáveis. Muitas empresas buscam preencher vagas para suas estratégias de expansão, ampliando a versatilidade organizacional e propiciando o surgimento de novas formas flexíveis de gestão (HAUBRICH, FROEHLICH, 2020). Para Tremblay (2002), o principal interesse das empresas é aumentar a presença em diferentes partes do país de origem e do mundo visando reter mais os trabalhadores ao permitir condições mais flexíveis de trabalho.

\subsubsection{Multiplicidade do termo}

O conceito de teletrabalho possui diferentes nomenclaturas, sendo chamado pela literatura no Brasil como: trabalho remoto, virtual ou simplesmente home-office.

O termo "home office" surgiu no contexto da crise do petróleo nos anos 70 , visando amenizar os problemas de trânsito, facilitados pelo desenvolvimento de tecnologias na época. Trata-se da mudança na forma de execução do trabalho, no qual as pessoas exercem suas atividades em casa, mantendo o vínculo com a organização (HAUBRICH, FROEHLICH, 2020). É considerado uma categoria específica dentro do contexto maior de teletrabalho, pelo fato de ser exercido especificamente em casa.

Já nos EUA, o termo mais frequente é o telecommuting, enfatizando a substituição do deslocamento entre o centro do trabalho e o local onde ele é de fato feito pelas ferramentas tecnológicas. Na Europa, utiliza-se o termo telework, com enfoque nas atividades realizadas de forma remota (ROCHA, AMADOR, 2018, p. 153)

Dada a multiplicidade do termo, Rocha e Amador (2015) afirmam que sua compreensão em geral está relacionada à atual tendência de atividades laborais serem realizadas com o uso de meios "telemáticos" sem necessidade de deslocamento do trabalhador ao local onde os resultados devem ser apresentados.

Para efeitos desta pesquisa, o termo a ser utilizado será trabalho remoto 
ou teletrabalho por englobarem tanto o trabalho exercido dentro de casa como em qualquer lugar com conexão para o mesmo. Isso se deve muito ao contexto de pandemia que trouxe o home-office como uma saída possível para muitos trabalhadores, mas aos poucos a opção por trabalhar em outros locais de forma remota tem sido também uma opção para muitas pessoas, incluindo os aqui entrevistados.

\title{
2.2.3 Contextualização nacional
}

No Brasil, o trabalho à distância foi inserido na legislação trabalhista pela primeira vez em 2011, com a Lei $n^{\circ} 12.551$. Essa mudança se deu através da alteração da redação do artigo 6 da Consolidação das Leis Trabalhistas (CLT), incluindo assim a modalidade de teletrabalho:

\begin{abstract}
Art. $6^{-}$Não se distingue entre o trabalho realizado no estabelecimento do empregador, o executado no domicílio do empregado e o realizado a distância, desde que estejam caracterizados os pressupostos da relação de emprego.

Parágrafo único. Os meios telemáticos e informatizados de comando, controle e supervisão se equiparam, para fins de subordinação jurídica, aos meios pessoais e diretos de comando, controle e supervisão do trabalho alheio (BRASIL, 2011).
\end{abstract}

Já em decorrência da ampla adoção do teletrabalho no país nos anos seguintes, foi assinada a Lei $n^{\circ} 13.467$ de 2017, trazendo um novo capítulo dedicado ao tema. No mesmo, foi definido como:

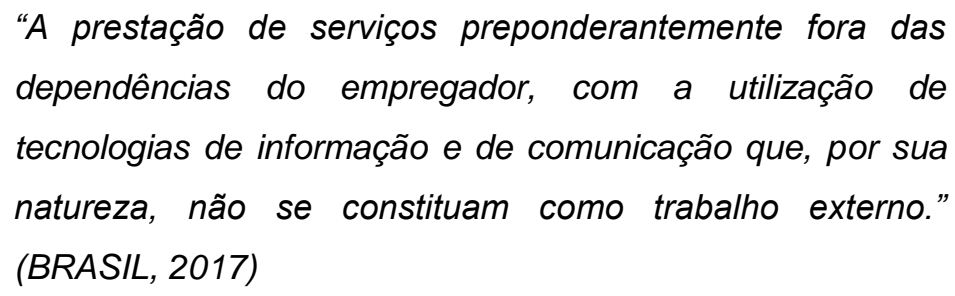

Por último, foram anunciadas a Medida Provisória 927 de 2020, além da Lei no 14.020 de 2020, visando o enfrentamento da pandemia do novo coronavírus. Foi permitido assim a alteração do regime de trabalho presencial para o teletrabalho, independente de acordos individuais e coletivos, dispensando o registro prévio da alteração do contrato de trabalho. A MP 927 
esteve em vigor apenas até julho do mesmo do ano, mantendo apenas os acordo feitos nesse período. (Manual do Teletrabalho, 2020).

\subsubsection{Benefícios e aspectos questionáveis do teletrabalho}

Alves (2008), aponta que as tecnologias da informação e comunicação (TIC) foram importantes para as transformações na geração, processamento e transmissão da informação, bem como para a instantaneidade no seu acesso e disseminação; na criação de redes informacionais; na diversificação das modalidades de conectividade; na desterritorialização das atividades e das conexões, as quais tiveram impacto sobre a redução da necessidade de mobilidade. Todos esses fatores afetaram diretamente a organização social e do trabalho, possibilitando uma quebra nas fronteiras espaço-temporais.

A literatura tem abordado o tema de formas distintas e às vezes contraditória, mas em geral destacam-se como os principais benefícios desse modelo de trabalho para os trabalhadores: o aumento da produtividade $\mathrm{e}$ motivação, economia de recursos financeiros e tempo de deslocamento, flexibilidade na jornada de trabalho, autonomia (ADERALDO e LIMA, 2017). Para Barros e Silva (2010), a menor exposição à violência e stress em deslocamento e redução de custos para empresa e para o empregado são fatores positivos dessa modalidade. Cabe citar também os benefícios para as cidades e bairros como diminuição de automóveis nas ruas e da poluição e um crescimento mais descentralizado.

Dessa forma, esse modelo pressupõe maior autonomia de organização pessoal e também profissional, aos trabalhadores, desde que garantido um suporte físico (ALVES, 2008). Tremblay (2002) destaca a maior flexibilidade de horários para os trabalhadores e também a possibilidade de realizar tarefas pessoais em horário comercial. Outro benefício do trabalho remoto é a ausência de distrações como as do escritório e coworkings, ajudando na concentração em tarefas individuais. (WAIZENEGGER, MCKENNA, CAI, BENDZ, 2020). Também aparece como opção aos desafios da jornada de trabalho e à flexibilização da gestão, podendo até ser utilizado como estratégia de retenção de jovens trabalhadores que buscam agilidade e desenvolvimento dentro das organizações. (ADERALDO, LIMA, 2017).

Por outro lado, alguns autores defendem que se trata de uma nova configuração de precarização do trabalho e exploração do trabalhador, como uma forma de dominação do mesmo (ROCHA, AMADOR, 2015). Para Aderaldo, 
Aderaldo e Lima (2017), o descontrole da carga de trabalho é o principal fator associado a esse tipo de exploração.

Tietze (2005) acredita que os efeitos negativos percebidos pelos indivíduos são o maior controle exercido pelas organizações, jornadas de trabalho mais longas e menor criatividade no trabalho. Barros e Silva (2010) afirmam que, apesar das economias, os gastos com equipamentos, energia e materiais diversos para seu mobiliário para garantir um espaço de trabalho adequado e ergonômico, podem ser bastante altos. Além disso, essa modalidade exige da organização ferramentas e cultura que facilitem a autonomia dos trabalhadores, provendo capacitação e preparando as lideranças. Conflitos familiares e no trabalho podem se tornar mais recorrentes com o convívio, impulsionados pelo isolamento e a cobrança (BARROS, SILVA, 2010). Essa fatores são também citados por Costa (2013), junto da dificuldade de desenvolvimento e a falta de supervisão.

Outras desvantagens citadas são a dificuldade da integração e vínculo do funcionário com a empresa e, por parte do empregador, as barreiras de controle impostas por uma relação virtual. Isolamento social, condições de emprego menos favoráveis, fragilização de relações familiares e menos oportunidades de promoção (ADERALDO, LIMA, 2017). Os autores afirmam que a sensação de isolamento pode reduzir a produtividade e a qualidade de vida, gerando uma alienação sobre a cultura organizacional. Outro ponto são os gastos com equipamentos, seleção de funcionários, preparo de lideranças e incentivos, na visão do empregador (ADERALDO, LIMA, 2017).

\subsubsection{Estágio e teletrabalho}

Após a discussão dos dois eixos principais desse trabalho, estágio e teletrabalho, a relação entre ambos se torna mais evidente durante a pandemia do COVID-19. Esse contexto fez com que muitos dos trabalhos oferecidos aos jovens passassem a ser parcial ou totalmente remotos e, se tratando de um período de aprendizado e desenvolvimento, a distância pode ser uma grande barreira para os jovens.

O estágio remoto é um grande desafio para gestores, líderes, professores e os próprios estagiários, trazendo reflexões sobre o papel do estagiários nas organizações, o tratamento recebido, as atribuições e atividades demandadas em um contexto de distância entre líderes e subordinados, além de muitos outros. 
Tendo em vista o referencial e o contexto apresentados, a metodologia pode ser devidamente explicada, contribuindo para esse campo de estudo tão recente e relevante.

\section{Metodologia}

\subsection{Tipo de pesquisa}

Esta pesquisa se caracteriza como qualitativa por procurar entender as percepções de estudantes construídas em suas experiências remotas de estágio. Segundo Creswell (2010), esse formato de pesquisa se caracteriza por ter o pesquisador como instrumento para coleta de dados, por ser indutiva, interpretativa e baseada nas percepções dos participantes.

\subsection{O perfil do sujeito de pesquisa}

A pesquisa teve como entrevistados estudantes universitários, selecionados a partir de dois requisitos:

Estar cursando Administração, Economia ou Comunicação Social no ano de elaboração do trabalho (2021)

Ter uma experiência de estágio de forma parcial ou totalmente remota de pelo menos cinco meses.

A escolha dos cursos se deve a uma característica em comum dos estudantes que acabam tendo maior dificuldade de se adaptar à realidade prática do trabalho por serem mais distantes daquilo que é ensinado nas universidades. Não houve restrição quanto a instituições de ensino, mas todos os entrevistados estudam em universidades privadas, sendo elas a PUC-Rio, Ibmec, FGV e Facha. O segundo critério está relacionado à necessidade de uma experiência de estágio remoto ou híbrido, foco principal da pesquisa.

A tabela 1 resume o perfil dos entrevistados: 
Tabela 1: Perfil dos entrevistados

\begin{tabular}{|l|l|l|l|c|c|}
\hline No & NOME 1 & IDADE & CURSO & PERíODO & $\begin{array}{c}\text { TEMPO DE } \\
\text { ESTÁGIO } \\
\text { PRESENCIAL / } \\
\text { REMOTO }\end{array}$ \\
\hline E01 & Andreia & 21 & Administração & $7^{\circ}$ & $0 / 5$ meses \\
\hline E02 & Bruno & 23 & Economia & $8^{\circ}$ & $0 / 10$ meses \\
\hline E03 & Caio & 22 & Administração & $7^{\circ}$ & $0 / 5$ meses \\
\hline E04 & Daniela & 21 & Economia & $8^{\circ}$ & $0 / 5$ meses \\
\hline E05 & Eduarda & 22 & Comunicação & $8^{\circ}$ & 1 ano / 6 meses \\
\hline E06 & Flavio & 23 & Economia & $6^{\circ}$ & $0 / 8$ meses \\
\hline E07 & Giovana & 23 & Administração & $8^{\circ}$ & 6 meses / 8 meses \\
\hline E08 & Helena & 28 & Comunicação & $6^{\circ}$ & 0 meses / 1 ano \\
\hline E09 & Ilana & 23 & Administração & $7^{\circ}$ & 10 meses / 6 meses \\
\hline
\end{tabular}

Fonte: elaborado pelo autor

1 Os nomes apresentados são fictícios, preservando a identidade dos entrevistados.

\subsection{Análise dos dados}

Creswell (2010) define a análise de dados como um processo que envolve reflexão contínua a partir de questões analíticas e anotações durante o estudo. Ao mesmo tempo que os dados são coletados, outros são analisados. Essa pesquisa teve como objetivo explorar padrões temáticos nas falas dos entrevistas, elaborando inferências a partir das mesmas. 


\section{Apresentação e análise dos resultados}

Nesta seção foram apresentados e analisados os resultados a partir da categorização das entrevistas dos estudantes. Foram criadas as seguintes categorias, para estruturar a análise dos relatos obtidos: "processo de ingresso e início do trabalho na empresa", "Experiência de trabalho" e "aprendizado". O quadro 2 resume as categorias criadas:

Tabela 2 - Categorias de análise

1. Processo de ingresso e início do trabalho na empresa

2. Experiência de trabalho

3. Aprendizado

Fonte: elaborado pelo autor

As categorias foram estruturadas de forma a contextualizar a categoria escolhida partir do referencial teórico e do roteiro de entrevistas, com vistas a apresentar a visão dos estudantes explicitada nas entrevistas e a comparar as referências teóricas com o material empírico.

\subsection{Processo de ingresso e início do trabalho na empresa}

O processo de ingresso na empresa refere-se ao conjunto de etapas de recrutamento e seleção pelas quais os candidatos passaram para entrar na mesma. Alguns entrevistados relataram grande dificuldade para encontrar vagas, sobretudo no período da pandemia, por consequência da queda de demanda do mercado de trabalho:

"Eu tive um pouco de dificuldade de achar algum lugar para trabalhar por conta da crise tinham poucas vagas. Consegui por indicação do meu pai." (Andreia, Administração)

"Foi difícil achar estágio. Com a pandemia, o mercado desaqueceu muito e fiquei mais de um ano participando de processos sem ir para frente." (Caio, Administração) 
"Pulverizei meu currículo e fiquei esperando. Me candidatei pra essa vaga em março, início da pandemia, e entraram em contato comigo no final de julho. Foi muito difícil conseguir. Não só por causa da pandemia, mas por questão de demanda da minha área." (Helena, Comunicação)

Todos os entrevistados fizeram processos seletivos totalmente online e as etapas foram compostas em sua maioria por testes como de raciocínio lógico, português e inglês, mas principalmente de entrevistas com gestores, responsáveis da área de recursos humanos e CEOs. Os relatos seguintes ilustram os principais aspectos dos processos vivenciados pelos entrevistados:

\footnotetext{
"Queriam saber as minhas habilidades, se sabia inglês, se sabia usar excel." (Andreia, Administração)
}

"Foram duas entrevistas online: uma com o CEO, queria saber o que eu estudava, o que gostava de fazer, disciplinas que gostava. Depois foi com a futura gestora pra ver se estava dentro dos requisitos. Com ela, foram perguntas mais voltadas para o financeiro, o que já havia feito, o que havia aprendido, se sabia de contabilidade, finanças" (Daniela, Economia)

"Recebi uma mensagem de uma professora do CEIEE da PUC, mandei a ficha, fiz uma redação. Sabia que era pra FGV, não qual área. Depois de três meses, recebi um e-mail com um estudo de caso para traduzir e fazer uma apresentação. O atual chefe gostou, fiz entrevista e comecei" (Caio, Administração)

"Foi mais direto, mandei o currículo, depois uma conversa com analista, no dia seguinte com o gestor, dois dias depois outra. Foi rápido, uma semana e tudo virtual" (Flavio, Economia)

"Não lembro certinho do processo, mas foi tudo online. Tinha as etapas normais, testes, tinha que mandar um vídeo também, um case com uma pergunta que eu não lembro pra responder. Depois foi entrevista com Gente e Gestão e com o Gestor. Foi pela plataforma da Gupy" (Giovana, Administração)

Em sua maioria, os entrevistados apresentaram preferência pelo modelo remoto para os processos seletivos, destacando principalmente a otimização de tempo e a praticidade, em comparação com os contratempos e desgastes ocasionados pelos deslocamentos na forma presencial. Aqueles que já haviam participado de processos presenciais, registaram o aspecto positivo do online, por conta da ausência de deslocamento.

"Senti que no online foi tudo muito mais rápido. É mais fácil marcar reuniões online por 'n' motivos: tempo, transporte etc" (Ilana, Administração) 
"Não tinha participado de entrevista presencial. Foi prático, o home-office diminuiu a distância para o recrutamento. Pelo meu lado, foi tranquilo porque eu estava mais confiante" (Flavio, Economia)

"Eu acho que foi muito mais fácil porque, enfim, não tem o deslocamento até cada etapa do processo seletivo, então dá pra você se inscrever em bem mais processos ao mesmo tempo e consegue conciliar com as aulas que estão online" (Giovana, Administração)

\section{Outro aspecto positivo está relacionado ao menor nervosismo nas entrevistas. Alguns entrevistados se sentiram mais à vontade em casa, diminuindo ou atenuando um pouco da pressão que uma seleção presencial geralmente ocasiona:}

"Participei de processo presencial na X. Além da praticidade do online, pra modular a questão do nervosismo, pra mim foi melhor, porque tem uma câmera, a questão da pessoa não perceber alguns sinais que estou nervosa. Pra mim foi positivo. De maneira geral, online pra mim foi melhor. Considerando que eu era junior, me sai melhor nas entrevistas. Não vejo pontos negativos no processo seletivo online" (Helena, Comunicação)

"Se fosse presencial, acho que ficaria mais ansiosa, teria mais "brancos". O presencial é uma experiência mais completa, mas foi possível fazer toda a troca online sem problemas. Para mim foi bom ter sido remoto porque a empresa não era do RJ, então caso fosse presencial não poderia ter participado e aprovada" (Daniela, Economia)

Há também, por parte de alguns entrevistados, uma percepção de conforto e segurança que a modalidade virtual ajuda a construir. Eles apontaram que se sentiram mais confiantes durante as entrevistas, o que contribuiu para suas contratações:

"Acho que como não teve dinâmica em grupo que geralmente tem, não teve aquela tensão com os outros candidatos assim. É melhor, você fica mais à vontade em casa" (Giovana, Administração)

"Foi bem rápido. As etapas foram todas online. Me senti mais confortável fazendo a entrevista em casa. No presencial, você fica mais nervoso" (Caio, Administração) 
Por outro lado, alguns destacaram que o processo presencial é positivo por permitir o contato com o espaço físico da empresa e observar aspectos que não se consegue no remoto, como postura, gestos e leitura corporal:

\footnotetext{
"Mas ao mesmo tempo não conhece o ambiente da empresa. Quando você faz uma entrevista presencial tem uma leitura corporal sua e de quem está te entrevistando em relação a você, a maneira como a pessoa se veste e se porta. Fica mais limitado online" (Giovana, Administração)

"Fiz outro processo seletivo presencial. A diferença é que presencialmente você tem mais noção do espaço que você possivelmente vai trabalhar, contato direto com a pessoa. Consegue observar coisas que virtualmente você não vê. Sendo presencial, tem um retorno visual real, tem a questão do tátil. Consegue ter uma noção melhor. "(Eduarda, Comunicação)
}

Ademais, alguns dos candidatos mencionaram uma possível assimetria de informações em etapas online, além de existir formas de burlar determinados testes ou avaliações:

"Por outro lado, pode ter mais assimetria de informação, consegue testar menos, posso estar colando, lendo coisas, posso ser mais extrovertido na câmera" (Flavio, Economia)

"Como já estava no meio da pandemia, eu estava acostumada, mas é estranho ser avaliada por um videoconferência, não sabe muito o que esperar. Você tem medo do link estar errado, se atrasar, ter algum problema. Tem uma tensão maior. No presencial, você sabe mais fácil que tá tudo certo" (Eduarda, Comunicação)

Com relação ao início do estágio, Schein (1988) afirma que quando o estagiário começa a trabalhar em algum lugar, acaba também se inserindo em uma cultura diferente, onde existem certas crenças e pressupostos básicos que são compartilhados por todos os membros. Na visão do autor, nesse momento o estagiário tem a necessidade de aprender essas normas de convivência. Bianchi e Rocha-de-Oliveira (2011) adicionam ainda que esse é um momento de descoberta dos significados sociais da organização na qual o jovem participa e sua interação com o mundo. 
Dada a condição de uma primeira experiência de trabalho, os entrevistados relataram dificuldades no processo de adaptação à dinâmica da organização e socialização, reforçadas pelas características específicas deste período e do regime de trabalho remoto. A maioria esperava uma experiência totalmente diferente:

\footnotetext{
"Tem sido difícil. Muito difícil organizar o tempo. Dei sorte de começar em um lugar pequeno e conseguir ver tudo, mas queria muito ter a experiência presencial. Esperava ser mais fácil focar e organizar. Se tivesse em um escritório, começaria a trabalhar e ficaria fazendo aquilo no tempo planejado. É difícil engatar em casa" (Caio, Administração)

"O início remoto é ruim. Estamos inseguros quando a gente entra e é difícil perceber se você está fazendo um bom trabalho, se seu chefe está gostando, não está" (Helena, Comunicação)

"O início foi tudo online, temos reuniões segunda, quartas e sextas com toda a equipe, em torno de 10 pessoas. Consegui conhecer todos logo no primeiro dia. Foi estranho. É diferente do dia a dia que você conhece as pessoas aos poucos, no online conhece direto. É muita informação no começo, contato até maior do que o presencial para ajudar os recém-chegados" (Ilana, Administração)
}

"Quase todo dia tinha reuniões do trabalho em horário de aula e quase todas as vezes dei mais importância para as reuniões de trabalho. A rotina era me encaixar nas reuniões de trabalho. Me moldei ao cotidiano do trabalho." (Flavio, Economia)

Observou-se que, no período pandêmico, o processo de ingresso dos estagiários nas organizações foi marcado por etapas concentradas em testes focados em competências mais técnicas como raciocínio lógico e inglês, além de muitas entrevistas com os mais diversos responsáveis. De forma comparativa entre os processos presencial e online, em sua maioria, os entrevistados destacaram que o primeiro é mais rápido e confortável, não exigindo deslocamento. Por outro lado, a falta de contato físico distancia os envolvidos em entrevistas e omite fatores relevantes como postura, gesto e leitura corporal de ambos os lados.

Sobre os primeiros meses da experiência de estágio, que tem como pressuposto o desejo dos estudantes de aprenderem e contribuírem nas 
questões que a empresa necessita, muitos entrevistados relataram certa dificuldade na adaptação, sobretudo ao levar-se em conta o contexto do trabalho remoto, reforçando a distância entre as pessoas

Assim, os desafios inerentes ao estágio não se restringem somente ao período de seleção e contratação, estendendo-se para toda a experiência e vivência que os jovens tem dentro das organizações após suas respectivas admissões.

\subsection{Experiência de trabalho}

O estágio, segundo a Lei $n^{\circ} 11.788$, é uma via de desenvolvimento para o mercado de trabalho, de forma que os jovens estejam preparados para iniciar sua vida profissional. Bianchi e Piccinini (2011) afirmam que o estágio é um mecanismo responsável por aproximar a escola, o aluno, as empresas e a sociedade, dando a esse aluno uma experiência prática fundamental para complementar sua formação.

Em paralelo, o contexto do trabalho remoto, segundo Barros e Silva (2010) tem como um dos maiores benefícios para os colaboradores a redução do tempo de deslocamento até os ambientes de trabalho. Além desse fator, outras duas grandes vantagens foram destacadas pelos autores: a autonomia de gestão do tempo e uma melhor conciliação de compromissos sociais, familiares e de trabalho. As três questões foram abordadas pela maioria dos entrevistados, sobretudo a ausência dos deslocamentos e ganho de tempo:

"Dá para fazer mais coisa em menos tempo porque não tem transporte, mas odeio que fico sentada na cadeira o dia todo [...] Mas acho que no remoto as coisas ficam mais organizadas, a pessoa tem que te mandar uma mensagem por escrito ou te explicar por zoom o que você tem que fazer. No presencial é meio "monta sei la o que", tenho a impressão que no remoto fica mais claro, organizado" (Giovana, Administração)

"[Vantagens] Vejo no pessoal como tempo, conforto, ficar menos cansado [...] O remoto ajudou muito no equilíbrio. A pior coisa era ir pra faculdade depois do estágio. Hoje não entro cansado na sala. Entro de saco cheio, mas não cansada fisicamente. Era horrível, por mim eu nem volto no presencial. O home-office e aula EAD ajudaram muito nesse sentido" (Ilana, Administração)

“Um ponto positivo é ganhar tempo. Eu não calculava que o trajeto poderia ser muito cansativo. Posso acordar mais tarde, posso inserir mais tarefas no meu dia a dia" (Helena, Comunicação) 
"Locomoção com certeza é ótimo, ganho muito tempo no dia. A parte de alimentação também, poder almoçar em casa, tenho uma dieta diferente, seria mais difícil comer na rua" (Caio, Administração)

Por outro lado, alguns estudos mostram que os estágios podem estar distantes de seu objetivo inicial, servindo de fonte de renda para os estudantes e mão de obra de baixo custo para as empresas, já que, em sua maioria, os trabalhos desempenhados são de baixo nível e repetitivos (Rocha-de-Oliveira, Piscinini, 2012). Essa postura por parte da empresa impede que o estudante desenvolva seu potencial ou que adquira novos conhecimentos relevantes (Bianchi e Piccinini, 2011). Callefi e Mello (2019), afirmam que nem sempre os estagiários tem as suas expectativas contempladas. Tal visão acerca do estágio foi compartilhada por uma minoria dos entrevistados:

\footnotetext{
"Achei que ela poderia ter me dado atividades mais importantes. Tenho a impressão que ela não confiou em mim. Passava muito mais coisas básicas, planiIhas, pesquisas. Não me senti muito responsável" (Andreia, Administração)

"Na minha visão, não batia muito com o que eu queria fazer da vida. Era chato, muito operacional. Isso talvez fosse para alguém de contabilidade. Não era puxado porque pessoas de outros cursos mesmo poderiam fazer. A palavra mesmo era chato. Fiquei com trauma do setor financeiro, até porque tinha medo de fazer besteira. Muito metódico. Você vira um robô" (Daniela, Economia)
}

"A maioria é muito repetitiva, controle de férias, organização de pastas" (Caio, Administração)

Além disso, o isolamento social é um dos fatores mais críticos dentro do trabalho remoto, podendo gerar desmotivação nos trabalhadores e também reduzir as interações e vínculos criados no ambiente de trabalho (Barros e Silva, 2010). Aderaldo, Aderaldo e Lima (2017) afirmam que esse fator pode vir a afetar inclusive a produtividade e a qualidade de vida dos colaboradores, gerando uma desconexão com a cultura organizacional. Especialmente no caso dos estagiários que estão buscando uma vivência mais profunda, esses fatores podem afetar ainda mais o trabalho e a vida em geral. $O$ isolamento social foi destacado como um fator negativo por todos os estrevistados:

"[Sobre relações] Não vejo coisas muito positivas [...] Com os outros colaboradores, não vejo como pode ser melhor. São apenas perdas. Proximidade, naturalidade, aprendizado. Depois que fui lá uma vez, já foi diferente, ver as pessoas" (Ilana, Administração) 
"Queria ter um horário fixo, em casa é difícil de manter o foco. Queria estar com as outras pessoas, se vendo e tendo trocas. " (Caio, Administração)

"Não esperava passar por isso [trabalhar remoto]. Foi uma quebra de expectativa, porque senti que não vivenciei $100 \%$ a experiência do estágio que é estar lá com outros profissionais. Não tive interação em grupo, trabalhos em conjunto, o que fez falta. Não vivenciei o grupo e o ambiente empresarial, foi o principal que eu perdi por estar remoto. Apesar disso, foi uma experiência válida" (Daniela, Economia)

Um dos aspectos negativos relatados foi a dificuldade de separar a vida pessoal e profissional, uma vez que tudo é feito no mesmo ambiente:

"E acaba misturando o tempo de trabalho, faculdade, sei lá de que. Você trabaIha mais, mais horas, com menos qualidade. Começa o dia, termina e ainda tem coisa para fazer de trabalho. É estranho ser tudo no mesmo ambiente [...] O presencial respeita mais o horário, porque as pessoas vão indo embora, consegue dividir o pessoal do profissional" (Flavio, Economia)

"Eu acho que a questão do remoto dificulta um pouco né, a questão do pessoal e do profissional, de saber um pouco do pessoal das pessoas" (Giovana, Administração)

Uma das especificidades do contrato de estágio é o tempo de trabalho reduzido e o entendimento bilateral de que é uma etapa ainda de muito aprendizado para os estudantes. Nesse sentido, o exagero de cobrança e o trabalho fora do horário combinado também foram destacados por alguns entrevistados:

"Comecei trabalhando muito mais do que deveria, tive dificuldade de gerir meu tempo e uma estratégia que eu encontrei foi estar muito perto das pessoas [... ] Eu como estagiária sempre trabalhei muito mais do que o cargo pedia. O remoto contribuiu pra isso. Não tinha um chefe mandando eu ir pra aula. Eu podia assistir a aula enquanto trabalhava, como fiz algumas vezes. O chefe não enxerga o próprio ato do estagiário de estagiar" (Helena, Comunicação)

"No início, achava que era tranquilo, não tinha muita coisa para fazer. Com o tempo, tinha muita coisa e chegou um ponto que eu achava que o trabalho que eu estava fazendo era igual ao de um efetivado muitas vezes. Mesmo trabalho, mas eu era estagiária" (Eduarda, Comunicação)

Outros entrevistados disseram que a cobrança e o exagero de fato existem, mas que eles fazem parte do processo de crescimento do estagiário, 
adquirindo novas responsabilidades e ganhando importância na organização. Esse fator foi destacado por duas pessoas que já haviam estagiado presencialmente, o que denota essa diferença da experiência para buscar mais responsabilidades:

"Não acho que é excessivo porque estou quase me formando. Tenho responsabilidades de analista, mas a cobrança não é de analista. É algo que eu queria, que eu estava buscando" (Ilana, Administração)

"Normalmente é bem justo [o trabalho], mas eles tratam estagiário como efetivado mesmo, não tem diferença" (Giovana, Administração)

Novamente, o distanciamento e a falta do "contato físico" relatado pelos estudantes é um fator especialmente negativo pois afetava o exercício de um conjunto de habilidades comportamentais, como trabalhar em equipe, tirar dúvidas e se comunicar de forma efetiva:

"Às vezes me sentia acuado de perguntar coisas. Por vezes preferi pesquisar durante uma hora do que perguntar e ter a resposta em três minutos. Não é eficiente. O contato foi o melhor na medida do possível, à distância. Equipe pequena, o que facilitou um pouco. Agora no presencial, já é mais natural" (Flavio, Economia)

"Mas o que perde muito é o contato físico, coisas que eu poderia entender em uma troca de corredor ou indo almoçar junto. Se você tem uma dúvida, tem que fazer reunião. É muita reunião e isso desgasta muito. Não desenvolve muita relação pessoal, acabava que era tudo trabalho. A troca informal não ocorre. Sempre sinto estou perdendo alguma coisa por não estar presencial" (Eduarda, Comunicação)

"Não é somente aprender o problema, mas ter imersão e sentir o ambiente, cultura. Uma dúvida é tirada muito mais rápido presencialmente" (Bruno, Economia)

Nesse aspecto, outra questão que surge são os ruídos de comunicação potencialmente gerados a partir do ambiente online e uma interação quase que assíncrona. Além disso, é difícil enxergar além da sua equipe, das suas tarefas, tudo tende a parecer mais abstrato, o que dificulta a adaptação dos novos estagiários e o entendimento que a organização é feita por pessoas diversas em áreas diferentes:

"O presencial ele transborda a questão materialista no sentido de passar um conteúdo para uma pessoa. No online você aprende e ponto final. No presencial te abre portas, para além desse conteúdo, entender o que a pessoa está querendo 
passar. Começo a olhar outras áreas também. Seja saindo para almoçar, pegando um copo d'água. É mais sinérgico. O online é muito previsível, menos emocionante" (Flavio, Economia)

"[...] Mas a gente fazia dailys com a equipe para ter uma ideia do que estávamos fazendo [..] Acho que as pessoas ficam mais distantes e acho isso um pouco ruim" (Giovana, Administração)

"Essa falta de interação, uma mensagem escrita soa mais dura como é. Ficamos suscetíveis a falha de comunicação e isso é ruim para quem está começando [...] O remoto me impactou porque eu tinha muita expectativa de conhecer pessoas, conhecer o local de trabalho, ir trabalhar em algum lugar. Era algo que eu tinha muito desejo. Aquele break no cafezinho, isso no remoto é quase impossível de acontecer. Só consegui conhecer as pessoas presencialmente. No slack ou email, não consegui conhecer mesmo as pessoas" (Helena, Comunicação)

Para uma das entrevistadas, a criatividade foi a habilidade mais afetada pela vivência no remoto, como consequência direta da pandemia que nos isolou não somente do trabalho, mas também da vida pessoal e lazer.

"No quesito criatividade me atrapalhou muito. Ela é alimentada no dia a dia. Eu acordar no meu quarto e ter que criar sem vivenciar nenhuma experiência foi muito difícil" (Helena, Comunicação)

Conforme abordado por Tietze (2005), ainda se destaca dentro do modelo remoto ou parcialmente remoto o maior controle exercido pelas autoridades e pelas organizações, tendo em vista que o acompanhamento presencial e direto não é possível. A flexibilização propiciada pelas tecnologias e pelo modelo remoto, reforça o controle sobre aqueles que não estão sendo vistos (ADERALDO, ADERALDO, LIMA, 2017). Em geral, os entrevistados não tiveram essa percepção, considerando a supervisão como natural do trabalho e, em alguns casos, sendo até reduzida, levando em conta as funções exercidas pelo estagiário:

“Nos primeiros meses, eu mandava pra alguém olhar por cima, ver se eu falei besteira ou não e manda pra cliente. Aconteceu algumas vezes, mas é bom errar também. A medida que peguei experiência, fui tendo mais autonomia e responsabilidade, botam o seu na reta mais. Foi um processo linear. Hoje quase não tem supervisão, está num estágio de confiança mútua. Se eu não entrego, todo mundo é impactado" (Flavio, Economia) 
"No início, quando não me sentia seguro mandava para eles sempre pra eles verem. Hoje em dia não tem controle, eu faço e disparo a informação. Quando tenho dúvida, pergunto" (Giovana, Administração)

"Temos uma reunião de manhã e tarde pra bater prioridades, porque as prioridades mudam toda hora. Duas reuniões diárias com os gestores. Eu gosto porque fico mais próxima deles e posso acionar eles sempre que preciso [...] Em outras empresas batia ponto, aqui não. A cultura da empresa é trabalhar mais porque tem bônus por vaga fechada. As pessoas não mandam parar, diferente do presencial que você vai embora" (Ilana, Administração)

"Ele me passa as tarefas e eu entrego. Fico com o celular perto, de olho nas demandas, mas não tem um controle recorrente" (Caio, Comunicação)

Dois entrevistados sentiram que seus supervisores não estiveram muito próximos ou disponíveis para ajuda durante o estágio, o que é um pressuposto da atividade. O remoto atrapalhou nesse sentido, porque alguns se sentiam mais receosos em tirar dúvidas, sem maior acompanhamento do que presencialmente:

"Perguntava algumas coisas pro meu chefe, mas ele não podia me dar tanto suporte" (Giovana, Administração)

"Estão acostumados a colocar alguém para sentar do lado do estagiário e ensinar tudo. Em casa, é difícil ficar procurando a pessoa. O acompanhamento é bem complicado. Senti que algumas vezes fui deixado de lado. " (Bruno, Economia)

"É o que todo mundo sente de ter dúvidas pequenas, não conseguir tirar e ficar empacado. Esse é o maior problema" (Giovana, Administração)

Ainda assim, alguns entrevistados relataram a necessidade de mostra a evolução de suas entregas, o que pode ser enxergado como uma cobrança e até uma forma de controle por parte de seus gestores:

"Relatório semanal de trabalho. Reuniões diárias de trabalho e chefe que cobra bastante. Ela pergunta como é que está, pede para ver as coisas [...] Sinto que tem um pouco de controle de horário. Já aconteceu de eu ter uma consulta, não a avisar e ela pediu que tivesse alinhado antes. Não é um controle explícito, é um controle implícito" (Helena, Comunicação)

"Quase todo dia temos uma daily para as pessoas se verem, trocarem, estarem a par do que os outros estão fazendo. No início, sentia que tinha que falar tudo que 
fazíamos para mostrar que eu efetivamente trabalhei, depois estava mais tranquilo. É uma forma de cobrança indireta" (Eduarda, Comunicação)

Aderaldo, Aderaldo e Lima (2017, pág. 524) afirmam que "a preocupação da visibilidade da empresa e comparação com pessoas do escritório são alguns dos principais fatores de apreensão dos teletrabalhadores", o que foi comentado por uma das entrevistadas acerca da dificuldade de visibilidade do trabalho e reconhecimento no modelo remoto, algo essencial para estagiários que buscam a aprovação e o aprendizado:

\footnotetext{
"Se tivesse presencial, talvez ela me visse fazendo o trabalho, eu pudesse conversar, mostrar mais meu trabalho. Aqui não queria ficar chamando ela o tempo todo e ela não me via trabalhar o tempo todo. Ela falava para eu provar que sou boa, mas era difícil fazer isso, somente com os trabalhos feitos" (Andreia, Administração)
}

Dessa forma, observamos a existência de diversas nuances dentro da experiência do estagiário no trabalho remoto, aspectos positivos e negativos, questionamentos sobre circunstâncias melhores.

Muitos entrevistados trouxeram a angústia de terem dúvidas acerca do trabalho proposto a eles e não conseguirem tirá-las de forma rápida e eficiente com seu superior ou outros colaboradores. Além disso, não sentiram muita cobrança por suas entregas e se sentiram isolados, distantes do convívio social tão esperado. Assim, cabe refletir se o objetivo de aprendizagem e crescimento profissional almejado com o estágio de fato cumpriu seu objetivo, elevando as habilidades e capacidades técnicas e sociais dos jovens.

\subsection{Aprendizado}

O estágio pode ser considerado como um complemento ao ensino da universidade, de forma que os alunos tenham alguma vivência prática e aprendizagem dentro das organizações. $\mathrm{Na}$ literatura, destaca-se $\mathrm{O}$ entendimento do estágio como uma via de preparação para o mercado de trabalho, como responsável pela inserção profissional dos jovens (OLIVEIRA, PICCININI, 2012). Conforme argumentaram Callefi e Mello (2019), os estagiários iniciam seu trabalho buscando aprender e ajudar a organização da forma que podem, visando uma experiência que gere um crescimento profissional para os mesmos. 
A pandemia e a implementação do trabalho remoto em massa foram um grande desafio para os estagiários, uma vez que a experiência presencial era dominante e vista como algo essencial antes desse período. Apesar da aparente dificuldade, a maioria dos entrevistados acredita que aprendeu e vem aprendendo bastante em seu estágio, sobretudo nos eixos de relacionamento com as pessoas, como se portar em um ambiente de trabalho, organização e autonomia:

"Ver de fato como funciona na prática uma empresa agregou bastante. Não tinha essa ideia, porque meu curso é muito teórico. Vi a importância do que eu fazia também. Entendi como era a vida real. Apesar de não ter a vivência e convívio do presencial, ajudou a ver a prática mesmo [...] Qualquer trabalho do setor financeiro vou ter mais facilidade de pegar. Também aprendi a lidar melhor com o tempo, por conta de todas as tarefas. Me sinto mais preparada do que antes " (Daniela, Economia)

"Cresci demais. [...] Consegui compor algumas habilidades que eu não tinha, cordialidade, como se portar em ambiente profissional. Completou uma lacuna que faltava na minha experiência. No pessoal, acaba sendo uma pessoa mais responsável, organizada e passa a olhar a vida com uma visão mais de trabalho. Eu hoje passo o dia com agendinha física, não é só trabalho, você ganha organização, sensatez. (Flavio, Economia)

"Tá sendo bem bom, uma curva de aprendizagem absurda. Se me perguntassem até Julho acho que não teria aprendido muito. De Julho pra cá, foi um crescimento absurdo. Entendo toda a cadeia, a produção, uma visão. Ainda tem muito o que aprender. (Giovana, Administração)

"Foi bom. Aprendi e estou aprendendo e me desenvolvendo. Me ajudou a ser mais objetiva e assertiva. $O$ fato de conhecer o ambiente de empresa, fazer benchmarking, crescer junto, fazer parte do crescimento da empresa foi muito legal. Autonomia, assumir responsabilidades no trabalho, ter segurança para errar, que meu erro não me define, que todas pessoas erram (Helena, Comunicação)

"Coisas simples como mandar e-mail para clientes, reunião com chefes, aprendi. Agora me sinto mais tranquilo, mais preparado para as próximas experiências, para outros processos seletivos. Aprenderia muito mais no presencial, seria muito mais rico". (Caio, Administração)

Quando se observa, a partir da ótica do trabalho remoto, muitos acham que poderiam ter crescido e se desenvolvido mais ainda no modelo presencial, evidenciando um problema inerente ao próprio formato de trabalho. Existe uma dificuldade no aprendizado de forma remota, sobretudo para os estagiários, que 
necessitam de maior acompanhamento inicialmente porque desconhecem daquele meio.

As principais dores relatadas foram a ausência de uma vivência real do ambiente de trabalho, relacionamento distante com outras pessoas e dificuldade no desenvolvimento de habilidades técnicas a partir do exemplo. A dimensão social foi bastante afetada segundo os entrevistados, se conectando com uma das grandes desvantagens do trabalho remoto, o isolamento social.

\footnotetext{
"Sinto que estou crescendo, mas o desenvolvimento no presencial seria maior porque seria mais desconfortável. Por necessidade, você se desenvolve mais, sai da zona de conforto. É mais fácil se esconder no remoto" (Bruno, Economia)

"Aprendi muito. Poderia ter aprendido outras coisas presencialmente, seria uma troca mais próxima. Certos aprendizados não passam porque você está na tela, não tem um retorno das pessoas. (Eduarda, Comunicação)
}

Em certa medida, cabe inclusive o questionamento se o modelo remoto de trabalho consegue preencher de forma aceitável os objetivos e princípios do estágio, como momento de aprendizagem, desenvolvimento profissional e inserção no mercado de trabalho. Aderaldo, Aderaldo e Lima (2017) afirmam que umas das desvantagens do trabalho remoto são a dificuldade da integração e vínculo do funcionário com a empresa e, por parte do empregador, as barreiras de controle impostas por uma relação virtual. Isso tem consequências sobre o aprendizado dos estagiários, que acabam por se sentir distantes do gestor e empresa como um todo.

Rocha-de-Olveira e Piccinini (2012) afirmam que que a inserção profissional está relacionada ao término dos estudos e o início de um emprego, relacionado com o curso realizado. Cabe indagar se o acompanhamento que é feito remotamente consegue substituir a vivência presencial, gerando a transformação que se espera nos estudantes:

"Poderia ter me desenvolvido mais se fosse presencial e em outra área, mas me desenvolvi bastante" (Daniela, Economia)

"Acho que aprenderia mais no presencial. O que faço é justamente o que eles fazem. Se eu estivesse ao lado deles, seria mais fácil. Ver o que fazem, como fazem, como falam com clientes, ia facilitar muito" (Ilana, Administração)

"Aprenderia muito mais no presencial, seria muito mais rico". (Caio, Administração) 
Uma das entrevistadas, se contrapondo a grande maioria dos entrevistados, disse que conseguiu se desenvolver melhor por conta do remoto, focando nas suas entregas e trabalhos que realmente importavam:

"Pensando no meu desenvolvimento, se eu tivesse só no presencial, não teria me desenvolvido tanto. Teria focado em outras questões como passar uma boa imagem, falar bem, ser bem relacionada, que é importante. Mas as minhas skills de entrega, organização, trabalho em equipe me ajudou. Não precisei dedicar tempo e energia no relacional" (Helena, Comunicação)

Dessa forma, observa-se que 0 aprendizado dos estagiários entrevistados durante o trabalho remoto foi muito desafiador, com dificuldades concentradas no relacionamento interpessoal, na ausência de uma socialização presencial nos ambientes das empresas e também nos aspectos mais técnicos. A maioria dos entrevistados relatou ter conquistado bastante aprendizado e crescimento no período, mas, em geral, também acredita que a experiência presencial poderia ter incrementado ainda mais os resultados pessoais e profissionais. 


\section{Considerações finais}

A proposta desta pesquisa foi entender como estudantes universitários perceberam e sentiram as suas experiências de estágios em modalidade parcial ou totalmente remota, iniciadas durante a pandemia do novo coronavírus. A principal motivação desta pesquisa foi decorrente da experiência particular do pesquisador e de questionamentos que foram suscitados durante o período de estágio, sobretudo sobre como as empresas lidariam com essa nova realidade de trabalho de jovens estudantes em suas primeiras experiências profissionais.

Assim, as principais questões se referem ao entendimento acerca das expectativas dos jovens sobre seus estágios e qual foi a realidade encontrada, na modalidade do estágio remoto; como o teletrabalho pode ter favorecido ou prejudicado essa experiência; quais os principais anseios e angústias dos jovens ao exercer o trabalho de forma remota.

Com esse objetivo foram entrevistados nove estudantes dos cursos de Administração, Economia e Comunicação Social de diferentes universidades privadas do Rio de Janeiro. Pôde-se observar que experiência de estágio é única e dependente de diversos fatores, como a empresa (tamanho e setor), o supervisor e os colegas. Porém, foram observados, em geral, aspectos considerados positivos na experiência remota, com destaque para dois fatores: a ausência de deslocamento e a capacidade de conciliar a vida pessoal e profissional.

Por outro lado, foram consensuais, também, os grandes desafios desse modelo como o isolamento social, distanciamento do supervisor e dos colegas e falta do "sentir" empresarial, baseado no ambiente. Tais barreiras são seguidamente descritas na percepção do teletrabalho para a grande maioria que vem experenciando esse modelo (FOLHA DIRIGIDA, 2021). Os benefícios também já vêm sendo discutidos em estudos recentes sobre o assunto: economia de tempo de deslocamento, flexibilidade na jornada de trabalho e autonomia (ADERALDO e LIMA, 2017).

Com relação às expectativas dos entrevistados, foi observado que a maioria ansiava e desejava por uma experiência prática em escritório, influenciada pelo modelo tradicional de trabalho presencial, visto como 
dominante em todo o século passado. O modelo remoto surpreendeu a todos, sobretudo devido ao contexto da pandemia, trazendo consigo benefícios e desafios, tanto para gestores quanto para estagiários.

Cabe destacar que, de forma geral, aqueles que tiveram uma vivência presencial anterior sentiram mais fortemente os benefícios do modelo remoto, justamente pela ausência de deslocamento e uma tranquilidade maior no dia a dia. Os que não tinham essa experiência não possuíam uma referência para comparação, mas argumentaram de forma consensual que a vivência presencial fez muita falta pra eles.

Os resultados desse estudo são relevantes, ao discutirem e evidenciarem as consequências que a pandemia do novo coronavírus trouxe para o mundo do trabalho, fortalecendo e, de fato, implementando o modelo do teletrabalho em praticamente todas as empresas do mundo. Essa nova forma de trabalhar tem consequências desafiadoras, sobretudo para aqueles que estão iniciando sua carreira profissional. Nesse sentido, o estudo pode auxiliar os próximos passos de líderes, gestores e empresas na condução e orientação de seus estagiários que venham a atuar na modalidade de teletrabalho e, também, para guiar esses estudantes para uma melhor experiência remota. As percepções aqui relatadas podem ajudar no acompanhamento dos estagiários por esse caminho desafiador do teletrabalho.

Esse trabalho de conclusão do curso de administração da PUC-Rio foi escrito em paralelo ao exercício de um trabalho híbrido, como analista, dentro da área de recursos humanos, se tornando um periodo bastante intenso e desafiador. A dificuldade de conciliar o compromisso acadêmico com o trabalho trouxe também muito aprendizado, revelando a forte ligação entre teoria e prática, fortalecendo os vieses da reflexão, leitura e escrita. 


\title{
6 Referências Bibliográficas
}

ALVES, D. A. Gestão, produção e experiência do tempo no teletrabalho. Porto Alegre: Universidade Federal do Rio Grande do Sul, 2008.

\author{
ADERALDO, I. L.; ADERALDO, C. V. L.; LIMA, A. C. Aspectos \\ críticos do \\ teletrabalho em uma companhia multinacional. Cadernos EBAPE. \\ BR, v. 15, n. SPE, p. 511-533, 2017.
}

ANDRADE, R. C. R.; RESENDE, M. R. Aspectos legais do estágio na formação de professores: uma retrospectiva histórica. Revista Multitexto. v.3, n. 01, 2015.

BRASIL. Lei no 12.551, de 15 de dezembro de 2011. (2011). Altera o art. 6 da Consolidação das Leis do Trabalho (CLT), aprovada pelo Decreto-Lei ํㅡ 5.452, de $1^{\circ}$ de maio de 1943, para equiparar os efeitos jurídicos da subordinação exercida por meios telemáticos e informatizados à exercida por meios pessoais e diretos.

Disponível em: < http://www.planalto.gov.br/ccivil_03/_ato20112014/2011/lei/l12551.htm>. Acesso em 11 de setembro de 2021

BRASIL. Lei $n^{0}$ 13.467, de 13 de julho de 2017. (2017). Altera a Consolidação das Leis do Trabalho (CLT), aprovada pelo DecretoLei oㅜ 5.452, de $1^{\circ}$ de maio de 1943, e as Leis $n^{\circ} 6.019$, de 3 de janeiro de 1974, 8.036, de 11 de maio de 1990, e 8.212, de 24 de julho de 1991, a fim de adequar a legislação às novas relações de trabalho. Disponível em: <http://www.planalto.gov.br/ccivil_03/_ato2015-

2018/2017/lei/L13467.htm>. Acesso em 11 de setembro de 2021

BRASIL. Lei no 14.020, de 6 de julho de 2020. (2020). Institui o Programa Emergencial de Manutenção do Emprego e da Renda; dispõe sobre medidas complementares para enfrentamento do estado de calamidade pública reconhecido pelo Decreto Legislativo no 6 , de 20 de março de 2020, e da emergência de saúde pública de importância internacional decorrente do coronavírus, de que trata a Lei no 13.979, de 6 de fevereiro de 2020; altera as Leis $n$ os 8.213, de 24 de julho de 1991, 10.101, de 19 de dezembro de 2000, 12.546, de 14 de dezembro de 2011, 10.865, de 30 de abril de 2004, e 8.177, de $1^{\circ}$ de março de 1991; e dá outras providências.Disponível em: < 
http://www.planalto.gov.br/ccivil_03/_ato2019-

2022/2020/lei/L14020.htm>. Acesso em 23 de setembro de 2021

BRASIL. Medida Provisória ํo 927, de 22 de março de 2020 (2020). Dispõe sobre as medidas trabalhistas para enfrentamento do estado de calamidade pública reconhecido pelo Decreto Legislativo $\mathrm{n}^{\circ} 6$, de 20 de março de 2020, e da emergência de saúde pública de importância internacional decorrente do coronavírus (covid-19), e dá outras providências. Disponível em: $<$ http://www.planalto.gov.br/ccivil_03/_ato20192022/2020/mpv/mpv927.htm>.

BARROS, A. M.; SILVA, J. R. G. D. Percepções dos indivíduos sobre as consequências do teletrabalho na configuração homeoffice: estudo de caso na Shell Brasil. Cadernos EBAPE. BR, v. 8, n. 1, p. 71-91, 2010.

BECKHAUSER, S. P. R. et al. Orientação de estágio em Administração: aproximando teoria e prática? Revista Brasileira de Ensino Superior, [s.I.], v. 3, no 1, p. 56, 2017. DOI: 10.18256/24473944/rebes.v7n1p56-77.

BIANCHI, G.; OLIVEIRA, S. R. As representações sociais dos universitários de Administração sobre a experiência de estágio. In: Encontro Anual da Associação Nacional de Pós-Graduação e Pesquisa em Administração, 35., 2011. Rio de Janeiro. Anais... Rio de Janeiro: ANPAD, 2011. 1 CD-ROM.

BRASIL. Lei no-11.788, de 25 de setembro de 2008. Diário Oficial [da] República Federativa do Brasil. Subchefia para assuntos jurídicos, Poder Executivo, Brasília, DF, 25 set. 2008. Cap I a VI.

CALLEFI, J. S.; MELLO NETO, G. A. R. Mão-de-Obra Barata: O Sofrimento no Trabalho de Estagiários. Revista Pretexto, v. 20, n. 3, p. 22-35, 2019.

COSTA, I. S. A. Teletrabalho: subjugação e construção de subjetividades.

Revista de Administração Pública, v. 41, n. 1, p. 105-124, 2007.

FOLHA DIRIGIDA. Estágio home office: modelo é desafiador, mas jovens veem benefícios. 7 de abril de 2021. Disponível em: < https://folhadirigida.com.br/mais/noticias/estagios/estagio-homeoffice $>$. Acesso em: 15 de junho de 2021;

LEITE, A. L.; LEMOS, D. D. C.; SCHNEIDER, W. A. Teletrabalho: uma revisão integrativa da literatura internacional. Contextus: Revista Contemporânea de Economia e Gestão, v.17, n.3, p. 187210, 2019. 
HAUBRICH, D. B., \& FROEHLICH, C. (2020). Benefícios e Desafios do 'Home Office' em Empresas de Tecnologia da Informação. Gestão \& Conexões, 9(1), 167-184. doi: 10.13071/regec.23175087.2020.9.1.27901.167-184

MANN, S.; VAREY, R.; BUTTON, W. An exploration of the emotional impact of tele-working via computer-mediated communication. Journal of managerialPsychology, v.15, n. 7, p. 668-690, 2000

Pandemia apresenta novos desafios para o trabalho remoto. Valor Econômico.

Disponível em:

$<$ https://valor.globo.com/patrocinado/deloitte/impactingthefuture/noti cia/2020/05/ 8/pandemia-apresenta-novos-desafios-para-otrabalhoremoto.ghtml>. Acesso em: 15 de junho de 2021.

OIT.Relatório da OIT destaca oportunidades e desafios na expansão do trabalho a distância. Recuperado de https:// nacoesunidas.org/trabalhando-a-qualquer-hora-em-qualquerlugarnovo-relatorio-destaca-oportunidades-e-desafios-naexpansao-do trabalho-a-distancia/ 2017.

ROCHA, Cháris Telles Martins da; AMADOR, Fernanda Spanier. O teletrabalho: conceituação e questões para análise. Caderno EBAPE.BR, v. 16, no 1, Rio de Janeiro, Jan./Mar. 2018.

ROCHA-DE-OLIVEIRA, S.; PICCININI, V. A construção do mercado de estágios em administração na cidade de Porto Alegre. Revista Pensamento Contemporâneo em Administração, [s.l.], v. 6, no 4, p. 29-48, 2012a. ISSN: 19822596.

ROCHA-DE-OLIVEIRA, S.; PICCININI, V. C. Uma análise sobre a inserção profissional de estudantes de administração no Brasil. RAM. Revista de Administração Mackenzie, [s.l.], v. 13, no 2, p. 6301-6301, 2012b.

ROESCH, Sylvia Maria Azevedo. Projetos de estágio do curso de administração: guia para pesquisas, projetos e trabalho de conclusão de curso. 1 ed. São Paulo: Atlas, 1996.

SAKUDA, Luiz Ojima. Teletrabalho: desafios e perspectivas. Dissertação (Mestrado em Administração) - Escola de Administração de Empresas de São Paulo/FGV, São Paulo, 2001.

SAKUDA, Luiz Ojima; VASCONCELOS, Flávio de Carvalho. Teletrabalho: desafios e perspectivas. O\&S, v.12, n. 33, Abr./Jun., 2005. 
SCHEIN, E. La cultura empresarial y el liderazgo: una visión dinámica. Barcelona, Espanha: Plaza \& Janes, 1988.

TIETZE, S. Discourse as strategic coping resource: managing the interface between "home" and "work". Journal of Organization change management, v.18, n.1, p.48-62, 2005.

TREMBLAY, D. Balancing work and family with telework? Organizational issues and challenges for women and managers. Women in Management Review, v.17, n.3-4, 2002

TREMBLAY D. G. Organização e satisfação no contexto do teletrabalho. Revista de Administração de Empresas (RAE), São Paulo, v.42, n.3, jul./set. 2002

Valoria, C. S., Czarneski, F. R. C., \& Machado, D. G. (2018). ATIVIDADE DE ESTÁGIO: UM ESTUDO ACERCA DA CONTRIBUIÇÃO PARA A FORMAÇÃO PROFISSIONAL, QUALIDADE DE VIDA E BEM-ESTAR DOS ESTAGIÁRIOS. SINERGIA. Revista Do Instituto De Ciências Econômicas, Administrativas E Contábeis, 22(1), p.77-86, 2018.

WAIZENEGGER, L., MCKENNA, B., CAI, W. \& BENDZ T. (2020). An affordance perspective of team collaboration and enforced working from home during Covid19. European Journal of Information Systems, 29(4), 429-442. doi: 10.1080/0960085X.2020.1800417

Manual do Teletrabalho (2020). Material Educativo produzido pelo Tribunal Superior do Trabalho. 


\section{Anexo 1: Roteiro de Entrevista}
1) Recrutamento e seleção

- Como foi buscar estágios durante a pandemia? Quais dificuldades e quais facilidades vividas durante essa busca?

- Como foi o seu processo de recrutamento? (O processo foi virtual, presencial ou híbrido? Quais etapas tinham?)

- Você já tinha participado de processos/etapas presenciais? Como você sentiu a diferença para o virtual?

2) Onboarding / início na empresa

- Como foi o começo do estágio na empresa?

- Teve algo presencial?

- Como foi começar a trabalhar de forma remota?

3) Rotina / Relações no trabalho

- Como é a sua rotina de trabalho no estágio na modalidade remota?

- Quais eram suas expectativas sobre o trabalho antes e depois de entrar neste estágio?

- O que foi mais marcante nesta modalidade à distância (positiva ou negativamente)?

- Como é a relação com os seus colegas de equipe na forma remota? Quais os pontos positivos e negativos do formato remoto para as relações?

- Como você tem equilibrado os estudos e o trabalho? O fato de ser remoto ajudou ou piorou nesse aspecto? Por que?

4) Supervisão / Controle

- Como a empresa faz a supervisão do seu trabalho?

- Como é sua relação com o seu chefe?

- Como é feito o controle do horário e da produtividade no seu trabalho?

- O que você acha das suas responsabilidades enquanto estagiário? Acha que a dinâmica de trabalho remoto influencia nesse aspecto? Se positivo, por que?

5) Aprendizado / crescimento

- Como você vê o seu aprendizado e crescimento dentro da empresa?

- Você acredita que se desenvolveu como esperava no trabalho?

- Acha que o trabalho remoto afetou o seu aprendizado e crescimento na empresa? Como?

- Como os conceitos teóricos aprendidos no ensino superior foram utilizados dentro do seu trabalho? (Alguma dificuldade/facilidade dentro da modalidade virtual?) 